\title{
Oral hairy leukoplakia in vertically and horizontally acquired HIV infection
}

\author{
D Nadal, B de Roche, M Buisson, R A Seger
}

\begin{abstract}
Two boys aged 7 and 8 years, respectively, with oral hairy leukoplakia as the sole clinical sign indicative for HIV infection are reported.
\end{abstract}

(Arch Dis Child 1992;67:1296-7)

Oral hairy leukoplakia, a mucosal lesion termed so because of its 'hairy' appearance, is commonly observed in adults with advanced HIV infection. ${ }^{1}$ We report on two boys aged 7 and 8 years, respectively, in whom physical examination revealed oral hairy leukoplakia as the sole clinical sign indicative for HIV infection.

\section{Case reports}

CASE 1

This boy was first seen in our outpatient clinic at the age of 7 years. He was referred because his mother had recently had encephalopathy due to AIDS diagnosed. The father was an intravenous drug abuser who died of an overdose shortly after the boy's birth. After an uneventful pregnancy, the boy was vaginally delivered at term. The neonatal period was uneventful. No information could be gathered about breast feeding. During infancy, the boy experienced recurrent upper respiratory tract infections that did not require antibiotic treatment or hospitalisation. At the age of 2 years the child moved with his mother to Ecuador. He returned to Switzerland only one month before referral. Except for several episodes of diarrhoea associated with amoebiasis his history was uneventful.

On physical examination the boy had height, weight, and head circumference on the third centile for age. Lymph nodes, liver, and spleen were not enlarged. Neurological and neuropsychological tests were normal. However, whitish, vertically oriented bandform lesions,

Division of

Immunology/

Haematology,

University Children's

Hospital,

Hospital,
Steinwiesstrasse 75,

CH-8032,

Zurich,

Switzerland

D Nadal

B de Roche

R A Seger

Institute of Virology, University Joseph Fourier, Grenoble, France

M Buisson

Correspondence to: Dr Nadal.

Accepted 21 June 1992 each $0.3-0.5 \mathrm{~mm}$ in width, were noted on the

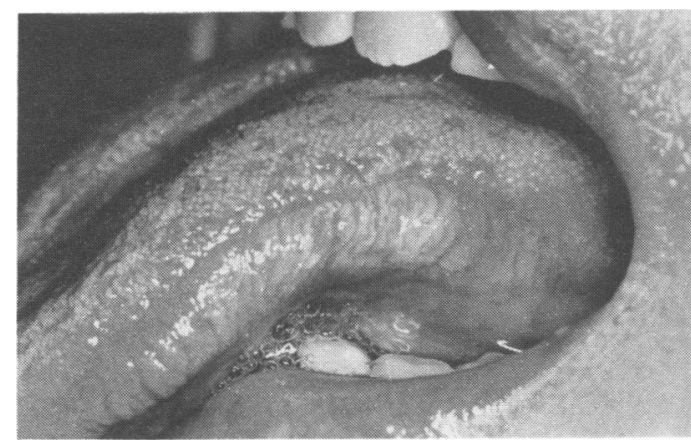

Clinical appearance of oral hairy leukoplakia. Note the characteristic vertical mucosal folds with the whitish lesions. posterolateral margins of the tongue (figure). The lesions could not be scraped off and a Gram stain of a swab showed no yeast. Epstein-Barr virus DNA was detected by Southern blot analysis of DNA extracted from cells scrubbed from the lesions and amplified using the polymerase chain reaction and two oligonucleotide primers from the Bam $\mathrm{Hl} W$ fragment of the virus. Chest radiographs showed no lymphoid interstitial pneumonitis. Infection with HIV was established by serology, detection of circulating p24 antigen, and positive viral blood cultures as well as polymerase chain reaction for HIV genome. The CD4+ cell count was $40 \times 10^{6} / 1$; lymphocyte proliferation to recall antigens was absent and poor to stimulation with mitogens.

\section{CASE 2}

This boy was referred at the age of 8 years. Because of recurrent episodes of fever, recurrent bronchitis, and increasing fatigue in the previous six months, his paediatrician had asked for the presence of antibodies to HIV to be tested as well as routine laboratory investigations; antibodies to HIV were present. The parents were seronegative for HIV. The boy's history revealed that he had been transfused packed erythrocytes at the age of 5 weeks when he was treated at another hospital because of sepsis. Then, serological tests for antibodies to HIV were not yet available. The blood donor, who since then had abstained from further donations, was traced and found to be infected with HIV. At the age of 4 years the boy had manifested haemolytic anaemia and thrombocytopenia that resolved after transfusion of intravenous gammaglobulin. HIV as possible cause had not been sought at that time.

On referral, the boy showed normal growth, slightly enlarged lymph nodes, and no hepatosplenomegaly. On both lateral margins of the tongue whitish lesions were noted. These lesions were similar to the ones reported in case 1 . Also, as in case 1, Epstein-Barr virus DNA was detected in scrape material from the lesions. Peripheral blood was positive for HIV genome by polymerase chain reaction and grew HIV in culture. No lymphoid interstitial pneumonitis was seen on chest radiography. The CD4+ cell count was $50 \times 10^{6} / 1$; there was no proliferation of the lymphocytes to stimulation with recall antigens or mitogens.

\section{Discussion}

In adults oral hairy leukoplakia is, in the 
absence of long lasting iatrogenic immunosuppression, ${ }^{2}$ pathognomonic for HIV infection. ${ }^{1}$ Association with progression to AIDS within few months is common. Epstein-Barr virus has been implicated as cause of the lesion. ${ }^{1}$ Distinction from thrush, which can be removed mechanically and be recognised by Gram stain, is easy. Differential diagnosis includes the rare white sponge naevus, frictional keratosis, some forms of lichen planus, and idiopathic leukoplakia. There is no established treatment for the lesion itself. ${ }^{3}$

We have found only one child reported in the literature, aged $8: 3$ years, who had oral hairy leukoplakia. ${ }^{4}$ So far, the disorder seems to be rare in children infected with HIV. But this may be due to the relatively long interval between acquisition of HIV and manifestation of the mucosal lesion. Horizontal transmission of HIV via blood products as in case 2 should be prevented now that the routine testing of donors for antibodies to HIV has been introduced. However, with the AIDS epidemic ongoing, a growing number of children vertically infected with HIV can be anticipated. As a large proportion survives longer than six years, ${ }^{5}$ many of these children will reach school age and may be oligosymptomatic or even asymptomatic, as in our case 1. Infection with HIV may therefore go unrecognised, especially when the parents are not aware of a risk for HIV infection or when they do not report such a risk while they are relatively well. Thus, in asymptomatic children seen by a general practitioner, for example for routine immunisation, oral hairy leukoplakia may be the sole sign indicative for HIV infection. Hence, simple careful clinical examination may lead to diagnosis and have an important impact, because advanced immunodeficiency may demand antimicrobial prophylaxis against opportunistic agents or initiation of antiretroviral treatment.

1 Greenspan JS, Greenspan D, Lennette ET, et al. Replication of Epstein-Barr virus within the epithelial cells of oral 'hairy' leukoplakia, an AIDS-associated lesion. $N$ Engl f Med 1985;313:1564-71.

2 Schmidt-Westhausen A, Gelderblom HR, Hetzer R, Reichart PA. Demonstration of Epstein-Barr virus in scrape material of lateral border of tongue in heart transplant patients by negative staining electron microscropy. $\mathcal{J}$ Oral Pathol Med 1991;20:215-7.

3 Katz MH, Greenspan D, Heinic GS, et al. Resolution of hairy leukoplakia: an observational trial of zidovudine versus no treatment. F Infect Dis 1991;164:1240-1.

4 Greenspan JS, Mastrucci MT, Leggott PJ, et al. Hairy leukoplakia in a child. AIDS 1988;2:143.

5 Tovo PA, de Martino M, Gabiano C, et al. Prognostic factors and survival in children with perinatal HIV-1 infection. Lancet 1992;339:1249-53. 